\title{
University Business Internships: The Corporate Advantage
}

\author{
Gayle Webb White, (E-mail: fgw@saumag.edu), Southern Arkansas University
}

\begin{abstract}
Participation in a university internship program can give a firm a competitive advantage. The corporation can utilize the internship program to find hard-to-fill job positions, to perform work of a high caliber, to serve as realistic job previews, and to serve as no-risk trials for future employees. In addition, other advantages of internship participation include the ability to provide a source of less expensive labor, to be able to use the permanent employees more advantageously, and to judge the intern's ability to work as a member of a team, and to evaluate his/her human relations skills prior to offering permanent employment.
\end{abstract}

\section{Introduction}

W

ithout any doubt, business internships are valuable to the students as they (1) develop better interpersonal skills, (2) develop contacts with area business/key people and expand their networks, (3) learn to troubleshoot, (4) gain exposure to all areas of their disciplines, (5) see knowledge learned in the classroom applied, (6) gain team experience, etc. However, the flip side of the coin and the direction of this research is that the corporation is the true winner in a university internship program; the many advantages to the corporation of employing interns will be explored in this paper. The advantages to the corporation include:

\section{Find Hard-to-Fill Employee Positions}

The information technology position has traditionally been a hard-to-fill position as evidenced by the unusual means being employed to recruit in this area. Thus, internet interns and other technology-skilled interns are in the driver's seat with offers of $\$ 20$ an hour, benefits, and even stock options (Barack, 2000).

Cisco Systems CEO John Chambers "told an audience of cheering interns they would each receive 500 stock options - as long as they came back to work for the company after graduation." (Barack, 2000). Therefore, although such benefits as stock options, medical insurance, relocation assistance, housing stipends, etc., are usual for new hires at most corporations, these benefits are also appearing in packages designed to attract interns. Also, intern salaries have had to be raised. At Schwab.com, college interns earn $\$ 500$ to $\$ 600$ per week.

At Boeing Company, approximately five hundred college interns will spend the summer touring factories and talking shop with mentors in information technology. Leong speculates that "At a time when businesses are pulling out all the stops to recruit good IT candidates, internships are one more way to get "em while they're hot." (Leong, 1998).

In addition, one corporation is attracting the computer information systems and computer science intern by establishing virtual technology laboratories on the university campuses and hiring the university intern to work while continuing with his/her education. Cardinal Health, Inc., a Fortune 500 company, has set up virtual computer laboratories at Arkansas State University and Southern Arkansas University. The Cardinal human resource personnel fly in twice each year to interview the intern candidates. The orientation of the hired intern can be accomplished in one of two ways. If the student has a summer free of classes, he/she is assigned to a

Readers with comments or questions are encouraged to contact the authors via email.

.team located in California, Illinois, or Ohio. The student returns to campus in the fall and continues the work in the virtual lab with the team he worked with in the distant location. If the student cannot go for a summer internship with the company, the student is flown to Illinois for a three-day orientation and then returns to work in the virtual 
laboratory with a Cardinal team in a distant location. The virtual internship program begun at Southern Arkansas University in 1999 hired its first full-time employee in December 2000. This first student received a $\$ 40,000$ salary plus a generous signing bonus. Two additional students were hired in the spring of 2001. Cardinal Health, Inc. set up their two virtual laboratories at one of the largest universities and one of the smaller universities in the state. The Cardinal Chief Information Officer is a former university professor and knows the potential value of the university intern as a source to fill hard-to-find positions (White, 1999). Cardinal Health, Inc. is selling the intern on their culture so they will want to become a full-time employee upon graduation.

Michelle Woody, of J. P. Morgan and Co. Inc., is so sold on the value of the summer internship program as a means of recruiting quality employees that "the summer associate program is the main avenue for becoming a permanent hire at the firm." (Harrison, 1988). Ten years earlier Ms Woody worked as a summer associate at J. P. Morgan and later became their vice-president of corporate recruiting.

College internships have become a part of the way creative companies are recruiting (Smith, 1989). Northwestern Mutual, in discussing successful recruiting programs said that "agencies that offer college internships are using an effective recruiting tool." (Kelly, 1994).

\section{Perform Work of High Caliber}

The companies are expecting work comparable to that of a regular employee. Sluga, a senior at Ashland University in Ohio, worked as an IT intern for GE Lighting as a sophomore with the marketing/sales team to develop an electronic ordering guide built with Microsoft Access. The following year, she participated on a team and helped to develop a Web-based program to track applications for GE's Six Sigma projects, its company-wide quality improvement program (McGee/Mateyaschuk, 1999). In addition, Northwestern Mutual college interns receive a shortened version of the company's full-time training and enjoy the same commission schedule as fulltime agents (Mackey, 1995). Since many of the university internship programs are honors programs, the students have higher grade point averages and must have the recommendation of several faculty members. One can see that this would reduce the work for the human resource department as much of the pre-screening has already been done by the university (White/Trexler, 1998). The corporation would, thus, be given an opportunity to choose from the university's top students.

\section{Serve as Realistic Job Preview}

Since the internship exposes the future job holder to many differing aspects of the work over a period of time, the internship "may be more realistic than the usual 'typical day in the working life' booklets and videos" (Knouse/Tanner, 1999). Interns learn more realistically about work deadlines, interplay with co-workers, dealing with customers, etc. Interns may discover they are not "cut out" for a particular field of work (Dale, 1996). Many new hires do not realize that they do not match a position until they have been hired and are well into their training program. Participation in the internship program would give an employer an opportunity to see how a "possible" future employee might respond to training. With many companies averaging nearly forty hours of training per employee at a cost of over $\$ 2,000$ per employee (Anfuso, 1993), the internship would afford them an opportunity to see if an employee responded favorably to training programs prior to actually hiring. Employees who respond favorably to change after training are valued in today's market (Huey, 1993). Thus, a corporate internship program can save a company from mismatches in the hiring process.

\section{Serve as No-Risk Trial}

College internship programs offer employees a no-risk trial of potential employees. Typically, the intern works about 160-180 hours for the employer or about twenty eight-hour days; this is small investment of a no-risk nature for the corporation (Hite, 1986). The employer has an opportunity to "try out" a possible future employee without having to perform all the documentation required of a regular employee who is in a trial period. Since the intern is not officially a candidate for a future job but is simply employed for a short internship time period, the employer has an excellent opportunity to unofficially evaluate a possible new employee. With recruitment costs continuing to climb, this can be an added advantage for a company to become involved in a university internship program. 


\section{Serve as Source of Less Expensive Labor}

In the smaller firms, internships may be used "as a source of less expensive labor." (Knouse/Tanner, 1999). Examples would be the CPA firm who needs extra assistance in the spring during tax season, any firm who is undergoing a change in computer software, any firm with seasonal marketing positions, etc. When Lurie and Company in Albany, New York, were faced with a large project that involved converting records from one type of computer software to another, they decided to try interns. The managing shareholder, Gregory H. Lurie, found that he was able, with interns, to employ quality personnel and keep costs to a minimum. Lurie found that working with interns was "as easy as working with any other professional." (Dennis, 1996).

\section{Use of Permanent Employees More Advantageously}

With the use of the college intern, the permanent employees can spend even more of their time on the more demanding aspects of their jobs (Hite, 1986). The intern could serve as the replacement when an employee in on vacation rather than having to take a regular full-time employee from a job to cover for the vacationing employee.

\section{Allows Permanent Employees To Learn From Interns}

The permanent employees can "learn about the latest theories in college circles" (Hite, 1986). Cannon/Arnold's research revealed that "firms see enormous value . . as internships can provide them with new ideas." (Cannon/Arnold, 1998). For example, the intern may know the newest software packages or the recent tax law changes. In a small firm, where the owner/manager must wear many hats, the intern can cover some of the areas of needed expertise.

\section{Can Judge Ability for Teamwork}

The intern sponsor would have an opportunity to see how the intern works as part of a team. Large organizations around the world are restructuring their organizations around teams to increase productivity and innovation and to improve customer service (Dumaine, 1990). With the majority of corporations using teams to accomplish work objectives, future workers must be good "team" players. Many times the transcript, the resume, and references cannot reveal this ability prior to hiring. With an intern, the employer could observe first hand how the intern fits into jobs performed by teams.

\section{Can Judge Human Relations Skills}

The internship program would allow an employer to see the human relations skills of a possible future employee. Since more jobs are lost due to inability to get along with other people than through inability to do the work, this would be an added incentive to work with interns the company might later hire. The intern sponsor could observe the intern's ability to "work with others" which is a part of every recruiter's qualifications checklist when evaluating future employees (Lafiff/Penrose, 1997).

\section{Can Assist in Needed Curriculum Improvements}

Most universities evaluate the qualifications of the interns sent into the corporate world by asking the intern sponsor to evaluate the student intern at the conclusion of the internship experience. For example, Siena College of Loudonville, New York, routinely evaluates the interns via their sponsors. When comments from corporate sponsors indicated that students needed to improve their oral and written presentation skills, the college initiated a freshmen course to address the problem (Seifert and Baker, 2000). In addition, when the overwhelming percentage of the sponsors' comments are positive, this, also, goes into curriculum decisions.

\section{Conclusions and Recommendations}

Innovative, progressive corporations recognize the contributions that interns can make to an organization-from helping to secure employees in hard-to-fill slots to bringing fresh ideas into the corporation. It is time that educators in universities realized the value of these programs. In one study of 298 college graduates who participated in an internship program, one of the major findings was that "most students valued their internships primarily for the impact on their 
learning" (Eyler, 1995). More faculty need to accept the legitimacy of the internship program. In fact, faculty should not only accept but embrace an internship for the university students.

\section{References}

1. Barrack, Lauren (2000). "The Kids in the Corner Office," The Industry Standard, Picked up by Newsweek at HTTP://www.msnbc.com/news 457666, 5 page, September 14, 2000.

2. Cannon, J. Andrew and Arnold, Mark J. (1998). "Student Expectations of Collegiate Internship Programs in Business: A 10-year Update," Journal of Education for Business, Volume Seventy-three, Issue Four, March/April, 1998, 202-205.

3. Dale, Kevin W. (1996). "College Internship Program," FBI Law Enforcement Bulletin, Volume Sixty-five, Issue Nine, September, 1996, 21-25.

4. Dawn, Anfuso, (1994). "Staying a Stone's Throw Ahead of the Competition," Personnel Journal, January, 1994, 56.

5. $\quad$ Dumaine, Brian, (1990). “Who Needs a Boss?” Fortune, May 7, 1990. 52-60.

6. Dennis, Anita (1996). "The Next Generation," Journal of Accountancy, Volume One-hundred eighty-two, Issue Six, December 1996, 89-92.

7. $\quad$ Eyler, Janet (1995). "Graduates' Assessment of the Impact of a Full-Time College Internship on Their Personal and Professional Lives,” College Student Journal, Volume Twenty-nine, June, 1995, 186-194.

8. Harrison, Sheila (1988). "Experience Wanted: A Guide to Internships and Co-ops," Black Enterprise, Volume Eighteen, Issue Seven, February, 1988, 180.

9. Hite, Robert E. (1986). "How to Hire Using College Internship Programs," Personnel Journal, Volume Sixtyfive, Issue Two, February, 1986, 110.

10. Huey, John. (1993). "Managing in the Midst of Chaos," Fortune, April 5, 1993. 38-48.

11. Kelly, Nancy E. (1994). "Recruiting Smart: How to Get 'em, How to Keep 'em," Life Association News, Volume Eighty-nine, Issue Two, February 1994, 44.

12. Lafiff, James M. and Penrose, John M. (1997). Business Communications $5^{\text {th }}$ Edition, Prentice Hall, $1997,540$.

13. Leong, Kathy Chin. (1998). "IT Internships Make the Grade," Internetweek, Special Volume, Issue Sevenhundred eight, March 30, 1998, 31-33.

14. Mackey, Shawn C. (1995). “Achieving Success,” Manager's Magazine, Volume Seventy, Issue One, January, 1995, 16.

15. McGee, Marianne K. and Mateyaschuk, Jennifer (1999). "Educating the Masses," Informationweek, Issue Sevenhundred twenty-one, February 15, 1999, 61-68.

16. Seifert, Charles F. and Baker, Bonni Perrott (2000). "An Outcomes Assessment of an Internship Program," Academy of Business Administration's 2000 Global Trends Conference, Cancun, Mexico, December 18-23, 2000.

17. Smith, Katherine E. (1989). "Creative Recruiting," Folio: The Magazine for Magazine Management, Volume Eighteen, Issue Two, February, 1989, 149.

18. White, Gayle W. (1999). Interview with Kathy Brittain White, Senior Vice President of Information Management for Cardinal Health, Inc., July, 1999.

19. White, Gayle W. and Trexler, Anna R. (1998). "The Effectiveness of the Undergraduate Business Internship Program as Perceived by Students at Southern Arkansas University," Proceedings of the American Society of Business and Behavioral Sciences, February, 1998, Las Vegas, Nevada. 